\title{
EXPERIMENTAL INVESTIGATION OF A GRAPHITE-COMPOSITE INTERTANK SECTION FOR A REUSABLE LAUNCH VEHICLE
}

\author{
James Wayne Sawyer and Harold Bush \\ NASA Langley Research Center \\ Hampton, VA 23681 \\ (757) $864-5432$ and 3099
}

\begin{abstract}
$\underline{\text { Abstract }}$
The use of graphite-composites as primary structure is essential for the development of a cost effective single-stageto-orbit reusable launch vehicle (RLV). A full-scale segment of a graphite-composite intertank was designed and fabricated by an industry team and tested at NASA Langley Research Center as a part of the RLV technology development program. The intertank test component was approximately $3.0 \mathrm{~m}$ long by $6.7 \mathrm{~m}$ wide and included slightly less than a $90^{\circ}$ section of a cylindrical intertank. The test article was fabricated using graphite-bismaelimide composite material and consisted of a hat-stiffened skin with five ring frames. The stiffeners were secondarily bonded to the panel skin and the ring frames were mechanically attached. The test article was loaded to failure with a uniform compression load applied by 21 individually controlled hydraulic acturators. Resistance strain gages, linear variable differential transformers and video cameras were used to measure and record the test results. A linear finite element analysis of the test article and test fixture was performed. The test results verified the structural integrity of the intertank test article up to the design limit load. However, the test article failed in general skin buckling between the ring frames at a load 1.08 times design limit load. This load was considerably lower than the expected failure load. The cause of premature failure is being investigated. Good correlation of the test and analysis results was obtained for loads up to the design limit load.
\end{abstract}

\section{INTRODUCTION}

For the United States to remain competitive in launching spacecraft, it is necessary to develop a launch system that greatly reduces the cost required to place a pound of payload into orbit. Significant reductions in launch costs requires that the launch system operate more like a commercial airplane than like the present Space Shuttle. Such a launch system must be light-weight, robust, require little inspection and maintenance, and be designed with lowcost operations as a major design feature. An Access To Space Study was conducted by a NASA Committee (Anon 1994) to address this problem and a number of launch system options were evaluated. The committee recommended a fully reusable launch vehicle (RLV) single-stage-to-orbit (SSTO) concept (Becky 1994).

A cost effective SSTO launch vehicle must employ the latest in technology advancements to meet the weight, size, and payload launch goals. An assessment of the impact of recent technology advancements on launch vehicle dry weight was performed (Freeman 1994) and the results of that study showed that the use of graphite-composites as primary structure is essential for the development of a light-weight, cost effective RLV. Considerable advancements have been made recently in the introduction of composite primary structures to the design of an RLV through cooperative agreements between NASA and two industry teams, McDonnell Douglas Aerospace/Boeing Aerospace and Boeing North American/Northrop-Grumman (BNA/N-G) (Sawyer 1996 and Suh 1996). In these cooperative agreement programs, unique technical issues have been addressed for three major structural components-intertank, wing, and thrust structure. Major large-scale structural test articles, representative of each component, have been designed and fabricated, and have been tested to verify the design, analysis and fabrication technology (Sawyer 1997 and Suh 1997).

As a part of the cooperative agreement between NASA and BNA/N-G, a full-scale segment of a graphite-composite intertank was designed and fabricated by a BNA/N-G industry team and tested in static compression to failure at NASA Langley Research Center ( $\mathrm{LaRC}$ ). This paper describes the test program and presents and discusses the test results obtained. The test results are also compared with analytical results predicted by the BNA/N-G team.

\section{TEST ARTICLE DESCRIPTION}

An extensive trade study was conducted to identify an optimum graphite-composite structural intertank design for the RLV wing-body configuration selected for evaluation by the BNA/N-G industry team (Suh 1996). The trade 
study focused on structural weight but also considered producibility, durability, and inspectability. Various honeycomb sandwich and skin stringer graphite-composite structural configurations were evaluated. Rib and spar spacing were varied to obtain the best structural arrangement. Non-optimum factors due to joints and cutouts were applied to the calculated weights to derive realistic estimates for the intertank structural weight. Critical design loads were developed from a simulated RLV flight envelope. The controlling design condition was a compression load parallel to the longitudinal axis of the intertank corresponding to the maximum acceleration of the vehicle during ascent.

The trade study indicated that a graphite-composite hat-stiffened shell structure with internal ring frames resulted in the lowest weight design for an RLV intertank (Suh 1996). An RLV prototype intertank design was developed assuming that the payload bay would be located in the intertank and thus large non-load carrying payload bay doors would be required to be incorporated into the design. A full-scale segment of the prototype intertank design was selected as a test article to validate the fabrication, design, and analysis methods for large light-weight composite components. A cylindrical section of the hat-stiffened intertank shell including five ring frames was selected as the test component as shown in figure 1.

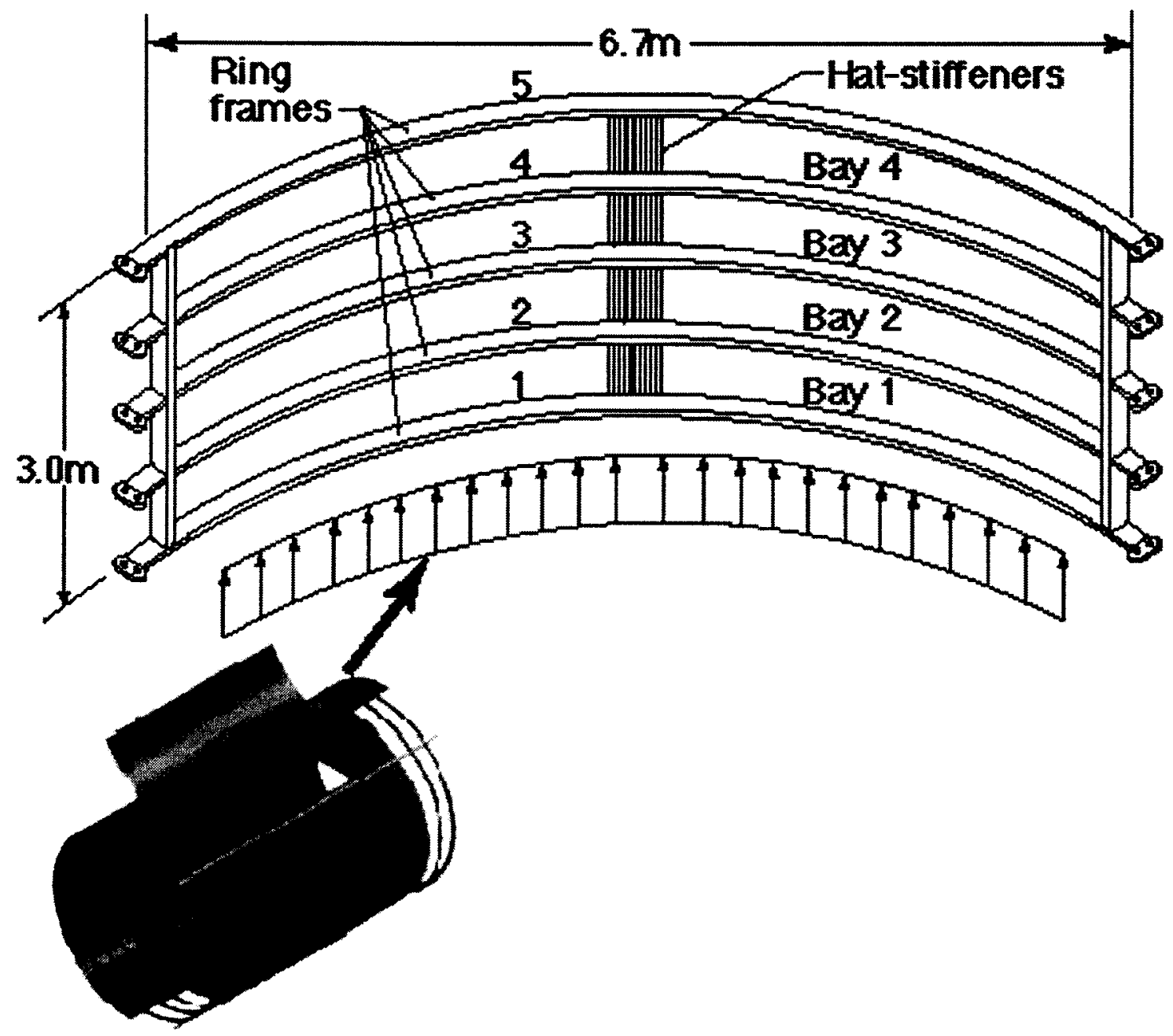

FIGURE 1. Intertank Test Article.

Several graphite-composite materials were considered for use in fabrication of the intertank test component. A material consisting of IM7 fibers embedded in a 5250-4 bismaelimide (BMI) matrix was selected because of its good fracture toughness and mechanical properties at temperatures up to $450 \mathrm{~K}$. Also the material has a large data base of mechanical properties and fabrication experience available for use in the design and fabrication of the test component. 
The central portion of the intertank skin between the 2nd and 4th frames is composed of 18 plies of unidirectional tape material with a symmetric ply orientation of $\left[ \pm 45^{\circ} / 90^{\circ} / 0^{\circ} / 90^{\circ} / 0^{\circ} / 90^{\circ} / \pm 45^{\circ}\right]_{s}$. The periphery of the intertank skin is strengthened by padding-up with additional plies of tape. Three sides (the two free sides and the load reaction end) of the skin have 12 additional plies added to the center of the lay-up to form a symmetric ply orientation of $\left[ \pm 45^{\circ} / 90^{\circ} / 0^{\circ} / 90^{\circ} / 0^{\circ} / 90^{\circ} / \pm 45^{\circ} / \pm 45^{\circ} / 0^{\circ} / 90^{\circ} / \pm 45^{\circ}\right]_{s}$. The load introduction end of the panel skin has 30 additional plies added to the center of the lay-up to form a symmetric ply orientation of $\left[ \pm 45^{\circ} / 90^{\circ} / 0^{\circ} / 90^{\circ} / 0^{\circ} / 90^{\circ} / \pm 45^{\circ} / 0^{\circ} / 90^{\circ} \mathrm{L} \pm 45^{\circ} / 0^{\circ} / 90^{\circ} / \pm 45^{\circ} / 0^{\circ} / 90^{\circ} / \pm 45^{\circ} / 0^{\circ} / 90^{\circ} / \pm 45^{\circ} / 0^{\circ} / 90^{\circ} / \pm 45\right]_{\text {s. }}$ A single layer of woven cloth is also applied to the intertank skin at all locations where holes are to be drilled to minimize the splintering where the drill bit exits. The stringers have a hat-shape cross-section and the ring frames have a channel (C-channel) cross-section. The hat stiffeners are composed of two plies of woven cloth on the side walls plus four zero degree unidirectional tape plies in the cap. The ring frames are composed of 12 plies of woven fabric with a symmetric ply orientation of $\left[0 \%+45^{\circ} / 0^{\circ} / 0^{\circ} \% \% 5^{\circ}\right]_{\text {s. }}$.

Both secondary bonding and co-curring were considered for attaching the hat stiffeners to the intertank skin. Numerous bonded and bolted sub-component joint specimens were tested during the design phase to evaluate the best attachment method. These sub-component tests were conducted at $200 \mathrm{~K}, 292 \mathrm{~K}$, and $450 \mathrm{~K}$ with the specimens dry and moisture conditioned for 10 days submerged in water at $355 \mathrm{~K}$. A photograph of a typical hat-stiffener-toskin secondary bonded joint specimen during a hat-stiffener pull-off test is shown in figure 2. Several sets of secondary bonded and cocured specimens fabricated using different techniques were tested. A secondary bonding technique resulted in the best attachment of the stiffener to the panel skin and was selected for use in fabricating the full-scale test article.

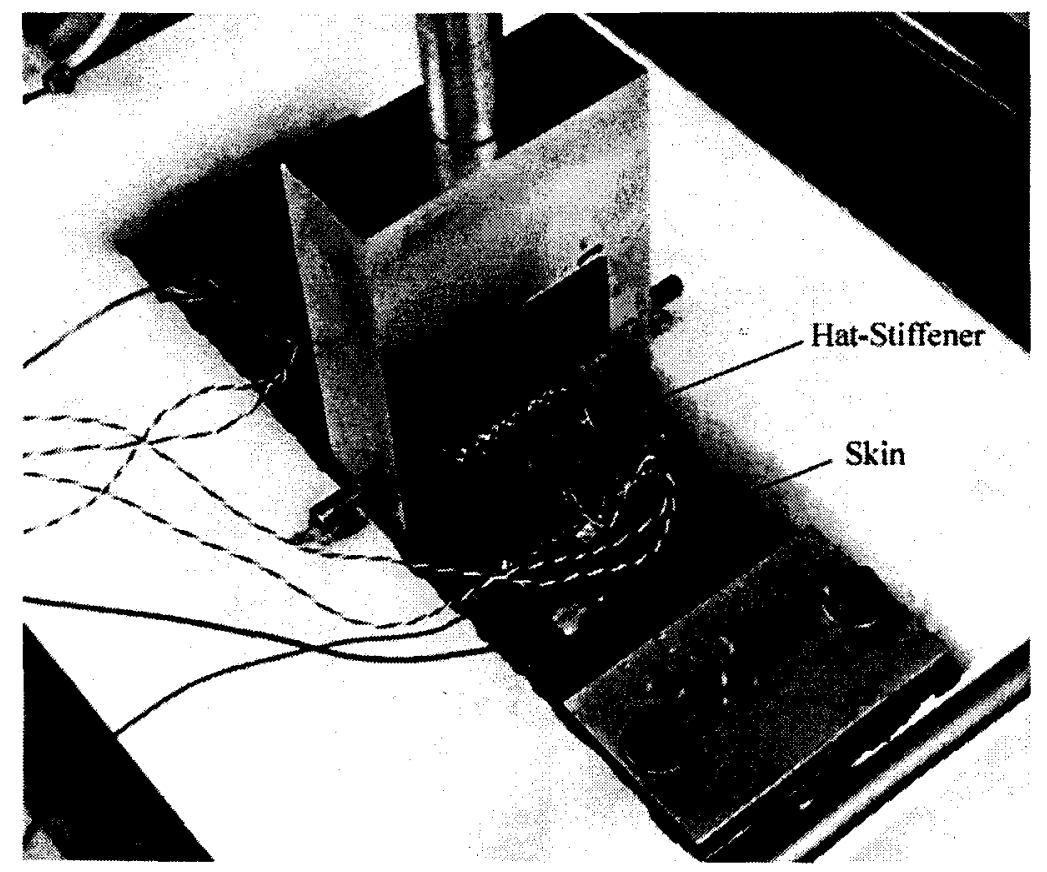

FIGURE 2. Skin-to-Stiffener Bonded Joint Spppecimen During Sub-element Pull-Off Tests.

The intertank test component was designed to meet RLV load and operations requirements in an area away from the payload bay doors. The test article is $3.0 \mathrm{~m}$ long, approximately $6.7 \mathrm{~m}$ wide, and includes slightly less than a $90^{\circ}$ section of the intertank as shown in figure 1. The panel skin is stiffened with 43 hat-shaped stiffeners secondarily bonded to the panel skin at $15 \mathrm{~cm}$ on centers. The ring frames are located at a $76.2 \mathrm{~cm}$ spacing. The three inner rings are fabricated using graphite-composite material and are mechanically attached directly to the stiffeners and to the intertank by means of composite shear ties as shown in figure 3 . The outer rings are fabricated from aluminum and are mechanically attached to the graphite-composite skin by means of heavy aluminum angle clips as shown in figure 4. Metallic end rings provide a more robust attachment for applying and reacting the component test loads and to reduce the fabrication costs for the test article. A photograph of the test article during assembly is shown in figure 5 and after assembly in figure 6. Aluminum side-edge fittings are shown attached to the composite ring frames in figure 6 and are used to support the ring frames during the test. 

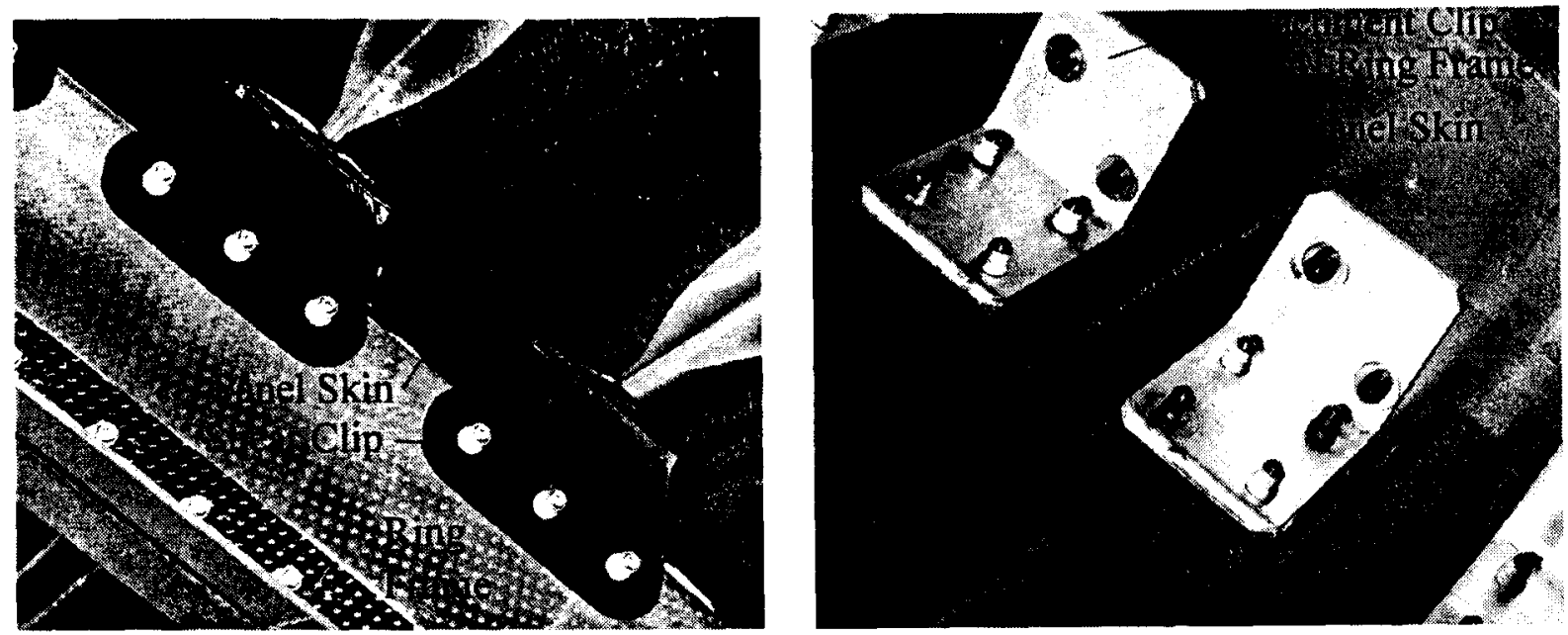

FIGURE 3. Mechanical Attachment of the Stiffeners to the Ring Frame.

FIGURE 4. Mechanical Attachment of the Aluminum Ring Frame to Composite Skins

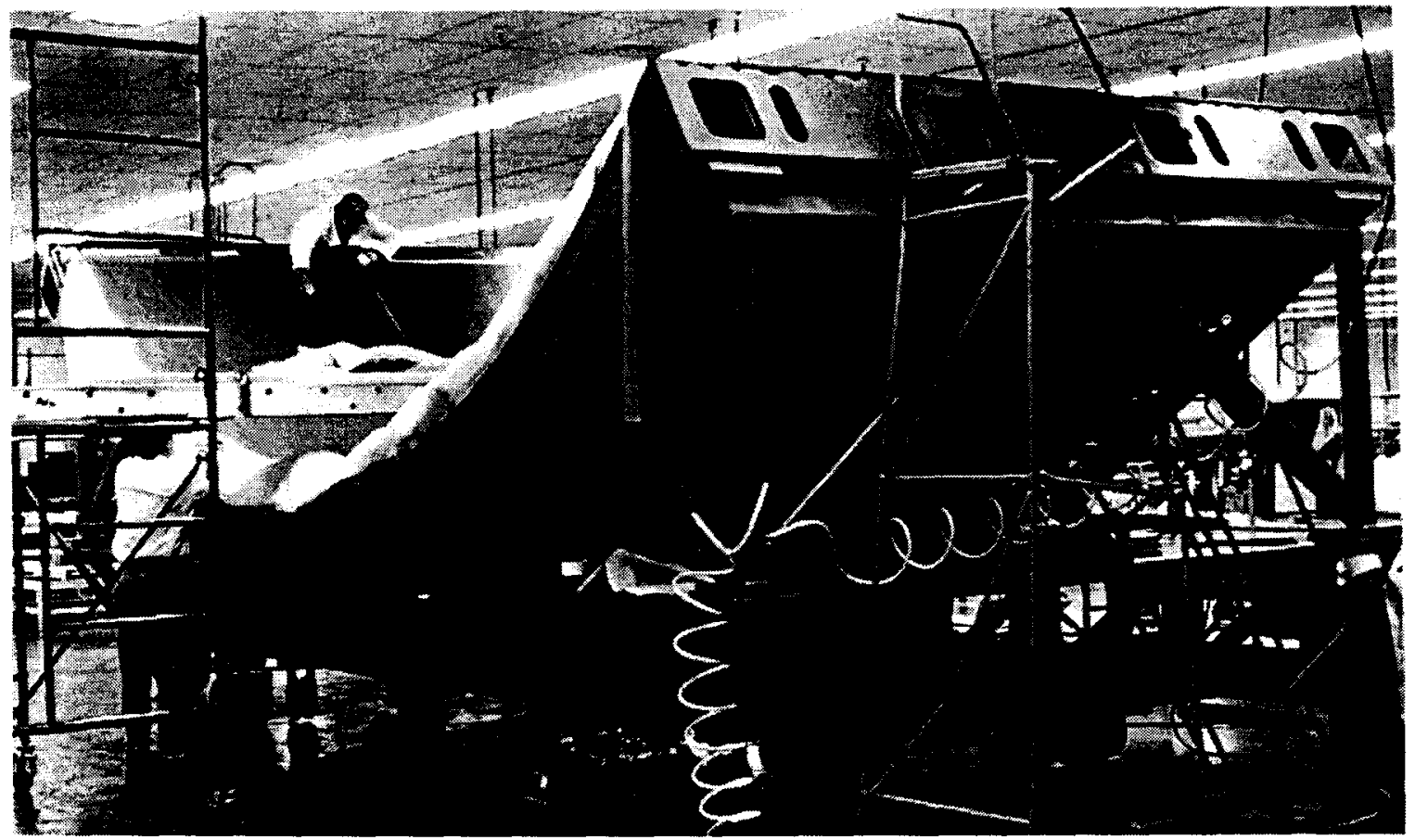

FIGURE 5. Intertank Test Article During Fabrication.

\section{SETUP AND TESTS}

The intertank test article was tested by subjecting it to a uniform compression load to simulate the vehicle critical loading condition. A schematic diagram of the test setup is shown in figure 7 . One end of the test article was attached to a stiff vertical support structure which serves as a flat platen and the other end was subjected to a uniform compression load through 21 hydraulic actuators equally spaced along the circular arc of the aluminum ring frame of the test article which acts as a load introduction fixture. The base of the hydraulic actuators were attached to a heavy aluminum reaction frame that was attached to the vertical support structure by two tension rods located near each actuator. The hydraulic actuators were attached to the aluminum ring frame and the reaction frame with clevis connections to eliminate local bending loads. The 21 actuators were divided into seven groups of three actuators and each group was individually controlled by feedback from a load cell to provide a uniform load to the test article. 


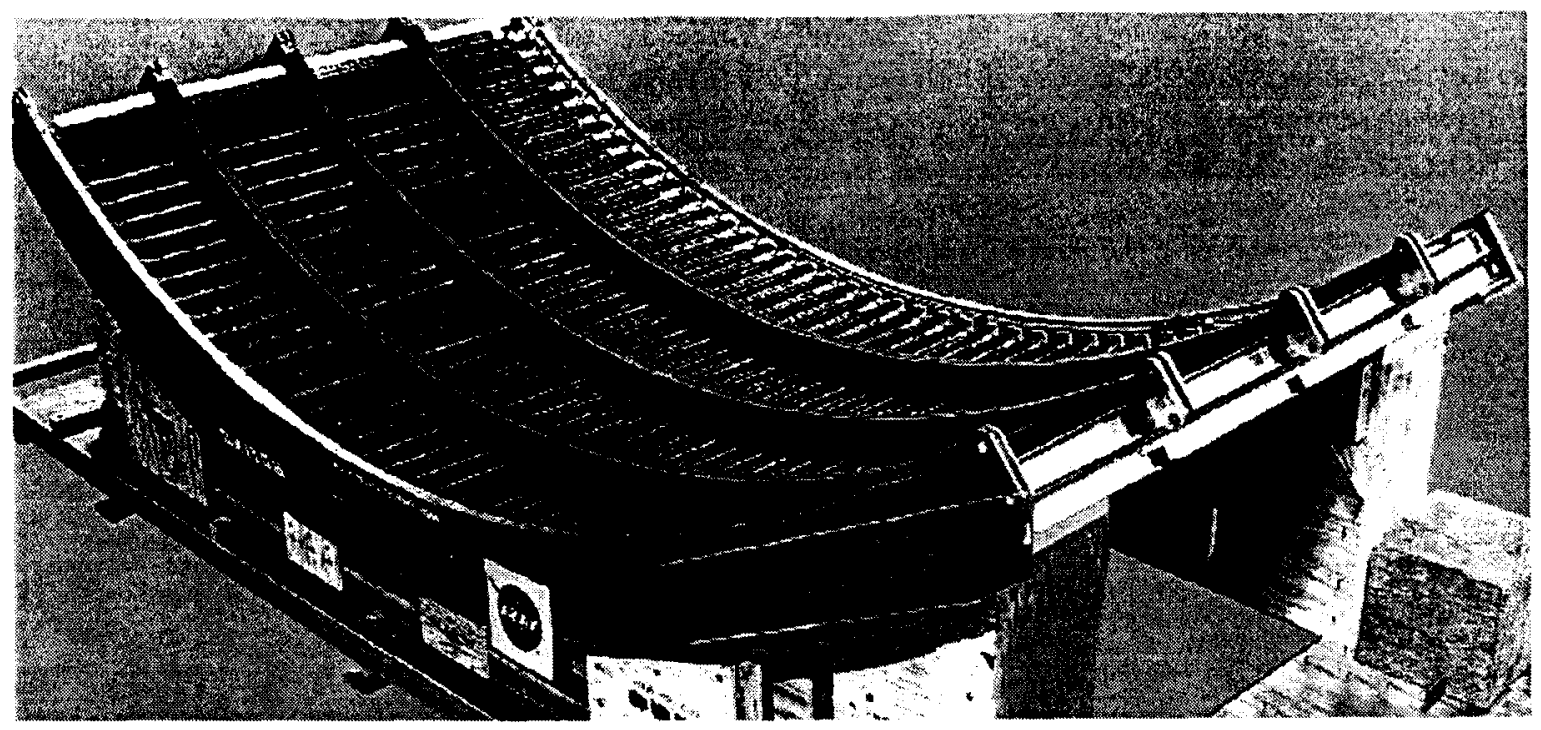

FIGURE 6. Intertank Test Article After Assembly.

Although the actuators were controlled in groups of three, the load from each actuator was measured and recorded by a load cell installed in-line with each of the actuators. The test article and the loading actuators are supported from the floor by stiff load frames attached to the ends of the composite ring frames, the aluminum load introduction fixture and the aluminum reaction frame. The support frames were bolted to the building floor but have pinned joints to restrict movement of the ring frames and the load fixtures in the radial and circumferential directions but allowed free movement in the direction parallel with the applied load. A photograph of the test article installed in the test fixture is shown in figure 8.

The test article was loaded to design limit load in one continuous load sequence at a rate of $180,000 \mathrm{~N} / \mathrm{min}$. The load was held constant at the design limit load for approximately 2 minutes while the test results were evaluated and the hydraulic system adjusted and then the loading was continued at a rate of $180,000 \mathrm{~N} / \mathrm{min}$ until structural failure occurred. Several low (less than 20 percent of the design limit load) load cycles were applied to the test article during installation of the hydraulic actuators and the development of the control systems. Four load cycles were applied to 40 percent of the design limit load during the final checkout of the controls and data acquisition system.

\section{INSTRUMENTATION}

The test article was instrumented with 305 resistance strain gages. The location of the strain gages is shown in figure 9. Most of the strain gages were uniaxial gages with the axis aligned parallel to the applied load and were located on the hat-stiffeners and the panel skin in the center of the panel bays between the ring frames. Fifteen strain gages were located on each of the three composite ring frames. In the panel bays located adjacent to the load introduction plate and the load reaction end, additional uniaxial gages were located close to the ends of the panel and bi-axial gages were located in the center of each of the bays to help evaluate how uniformly the load was being applied and distributed into the shell structure. Twelve linear variable differential transformers (LVDT) were used to measure the radial displacement of the center of each of the bays of the panel at locations shown in figure 9. Six additional LVDTs were used to measure the axial displacement and rotation of the aluminum load introduction ring frame to aid in assessing the uniformity of the load introduction into the shell structure. Data were recorded at the rate of 10 scans per second. One hundred and twenty strain gage channels and 8 displacement channels were displayed in graphical form as a function of the applied load and were monitored in real-time during the test.

Four still and four video cameras-one video and one still camera located on each side of the test article and two video and two still cameras located over the top of the test article-were used to record the test event. The video cameras run continuously throughout the test and the still cameras were used to take photographs at discrete times during the test. 

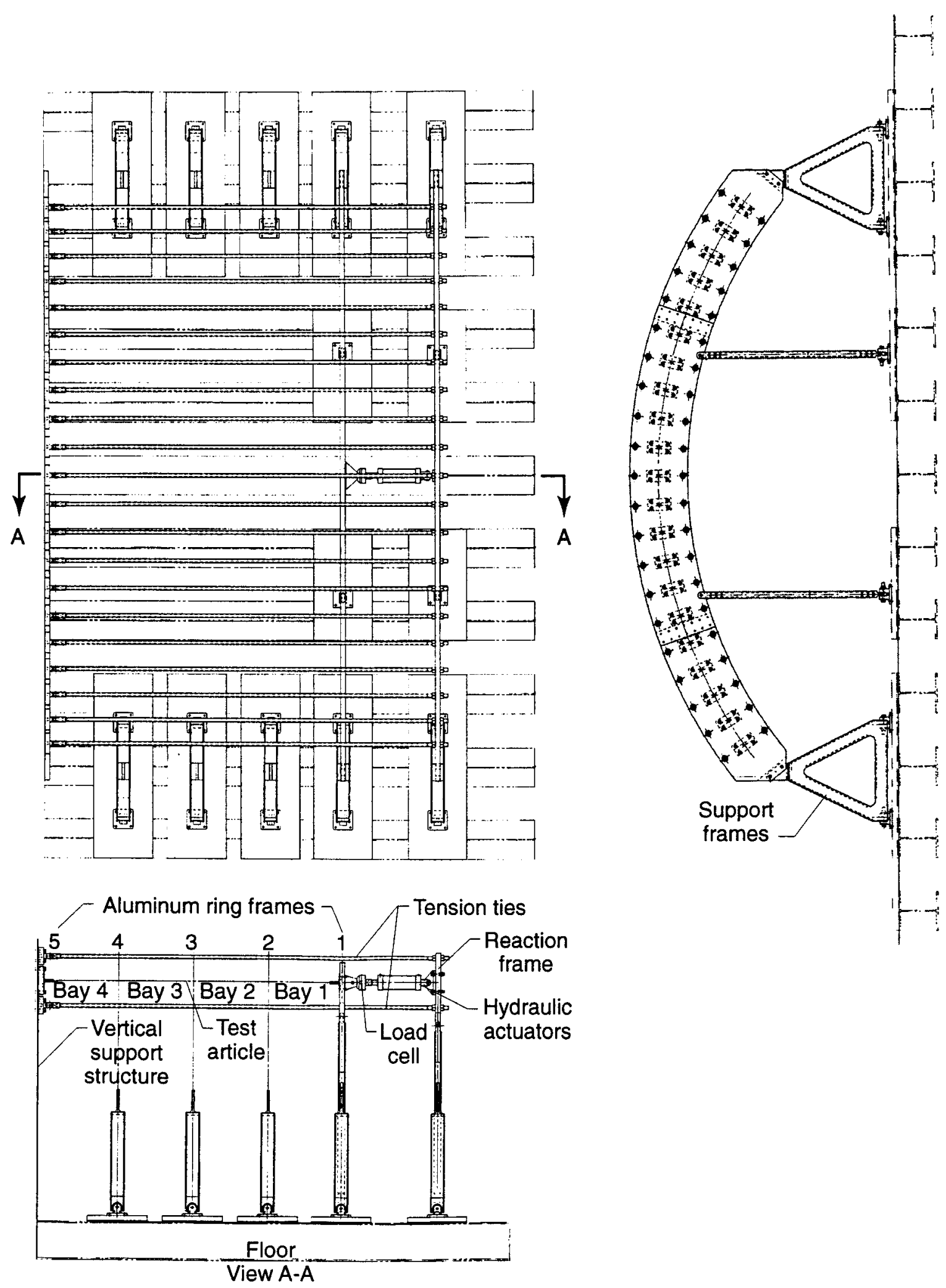

FIGURE 7. Schematic Diagram of Intertank Test Setup. 


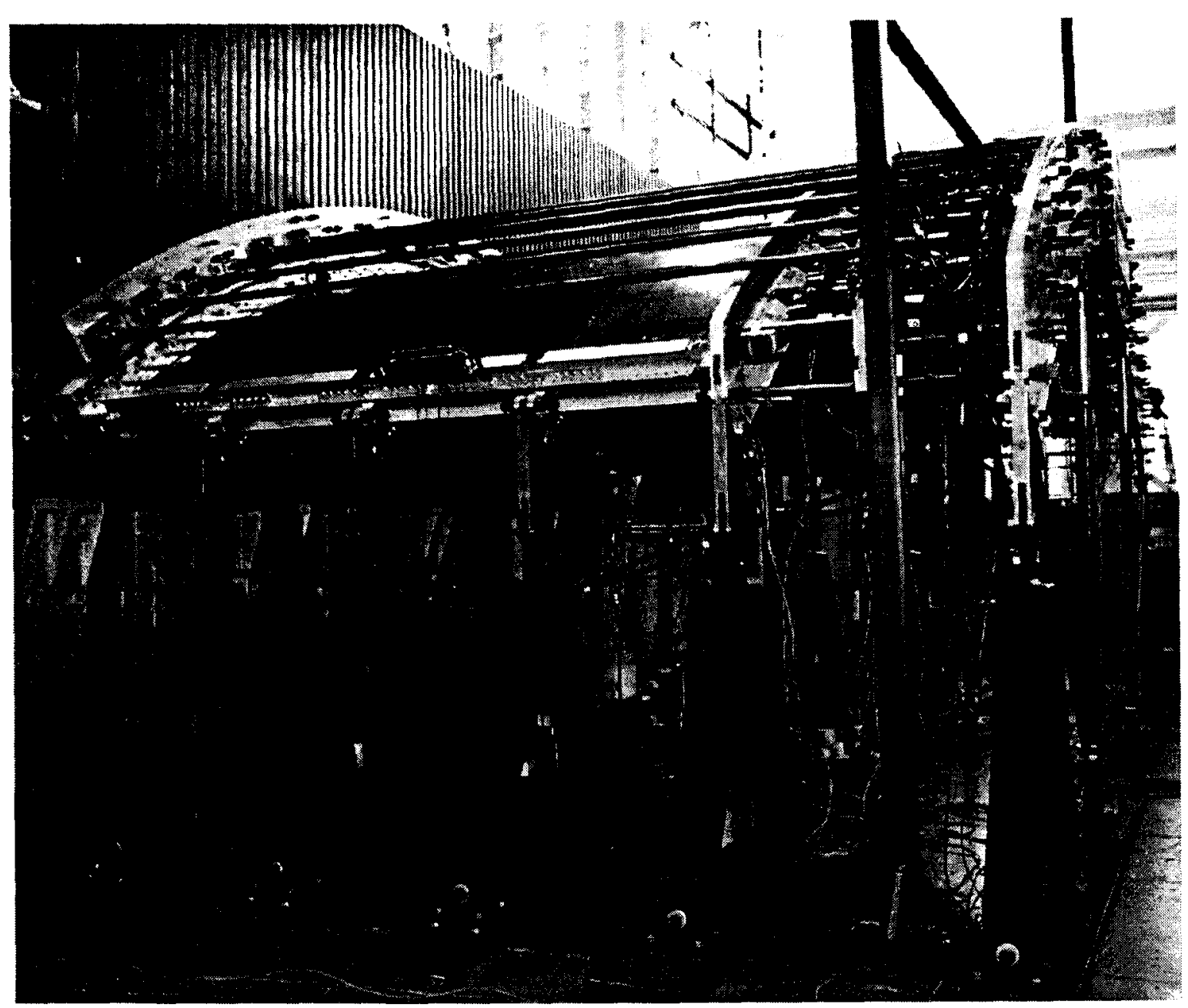

FIGURE 8. Test Article Installed in the Test Fixture.

\section{RESULTS AND DISCUSSION}

Selected test results are shown in figures 10-17. The loads applied to the test article and the resulting strains in the panel skin near the load introduction ring are shown respectively in figures 10 and 11 for the design limit load condition. Photographs showing the failure mode and structural damage at selected locations are shown in figures 12 and 13. Measured strains at selected locations on the test article are shown as a function of the applied total load in figures 14-17. Predicted strain values at the design limit load are also shown in figures 14-17 for comparison with the measured values.

The test results shown in figure 10 indicate that the test setup with the 21 hydraulic actuators resulted in a relatively uniform distribution of the loads applied to the test article. A maximum deviation of approximately 5 percent was observed over the loading area as a result of actuator number 6 exerting a low load. The other actuators (excluding number 6 ) showed less than a 1 percent deviation from the norm. The lower load exerted by actuator number 6 is probably due to a slight hyudraulic leak that deveoped during the test. Measured strain values in the panel skin near the load introduction ring (figure 9, section a-a) are shown in figure 11 as a function of the arc length from the left side edge of the test article normalized by the total arc length of the test article. Large variations over the width of the test article are obtained. At one location across the test article the measured strain is almost twice as large as at adjacent locations. These variations in the strain distribution are due to slight variations in the bolted attachments used to introduce the load into the composite skin as discussed previously. Since the strain measurements shown in figure 11 are relatively close to the aluminum attachment clips, it is expected that the load distribution becomes uniform before reaching the first composite ring frame. 


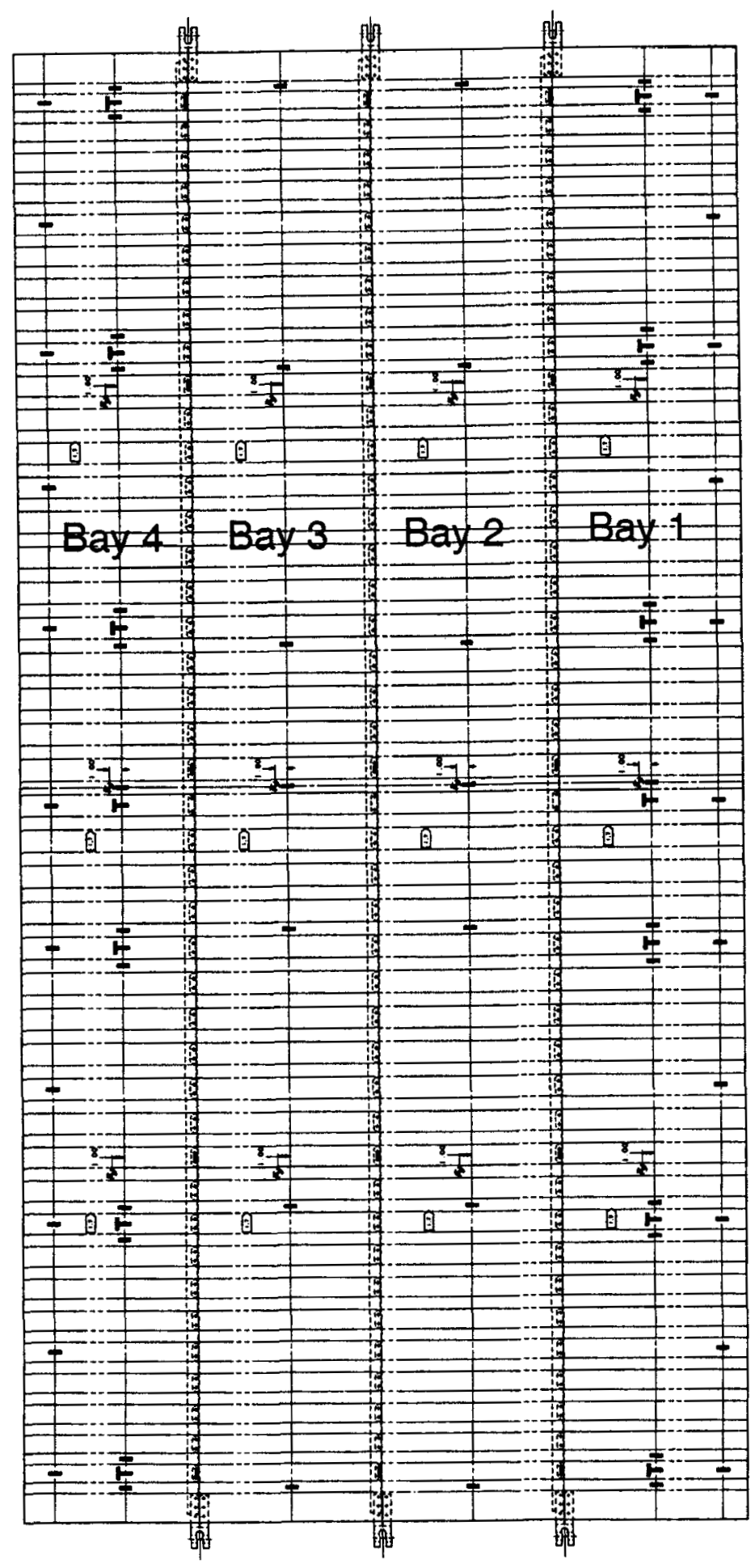

FIGURE 9. Location of Instrumentation on Intertank Test Article. 


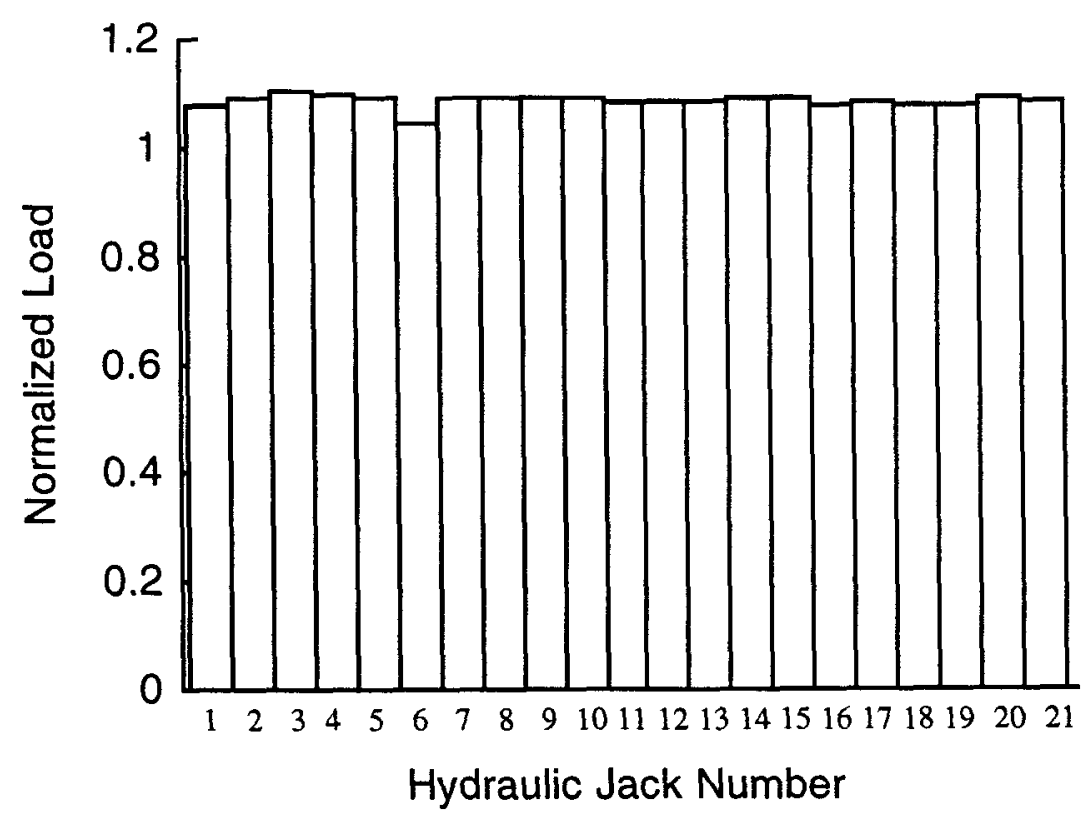

FIGURE 10. Load Distribution Applied to the Test Article at Failure.

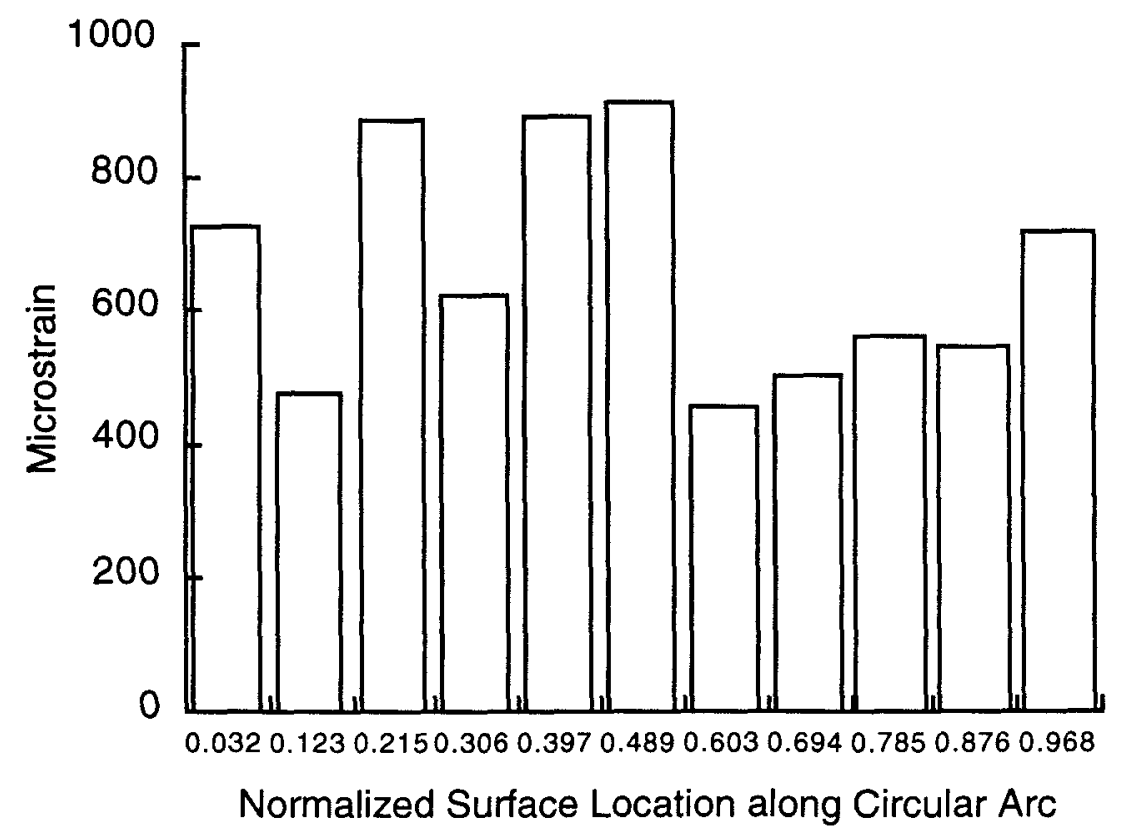

FIGURE 11. Strain Distribution Introduced into the Test Article at Design Limit Load.

Structural failure of the test article occurred at approximately 108 percent of the design limit load which was significantly lower than the predicted failure load. Review of the video tape data showed that failure resulted in general skin buckling between the third and fourth ring frames (third bay) from the end of the test article as shown in figure 12. Also, there was localized skin buckling on the right side of the test article in the second panel bay between the second and third ring frame. Review of the video tape frame-by-frame revealed that skin buckling started in the center of the panel skin in the third bay and propagated toward each side of the test article and into the right side of the second bay. There was no visible evidence of panel skin buckling in bays 1 and 4 near the load introduction and load reaction ends of the test articles. 


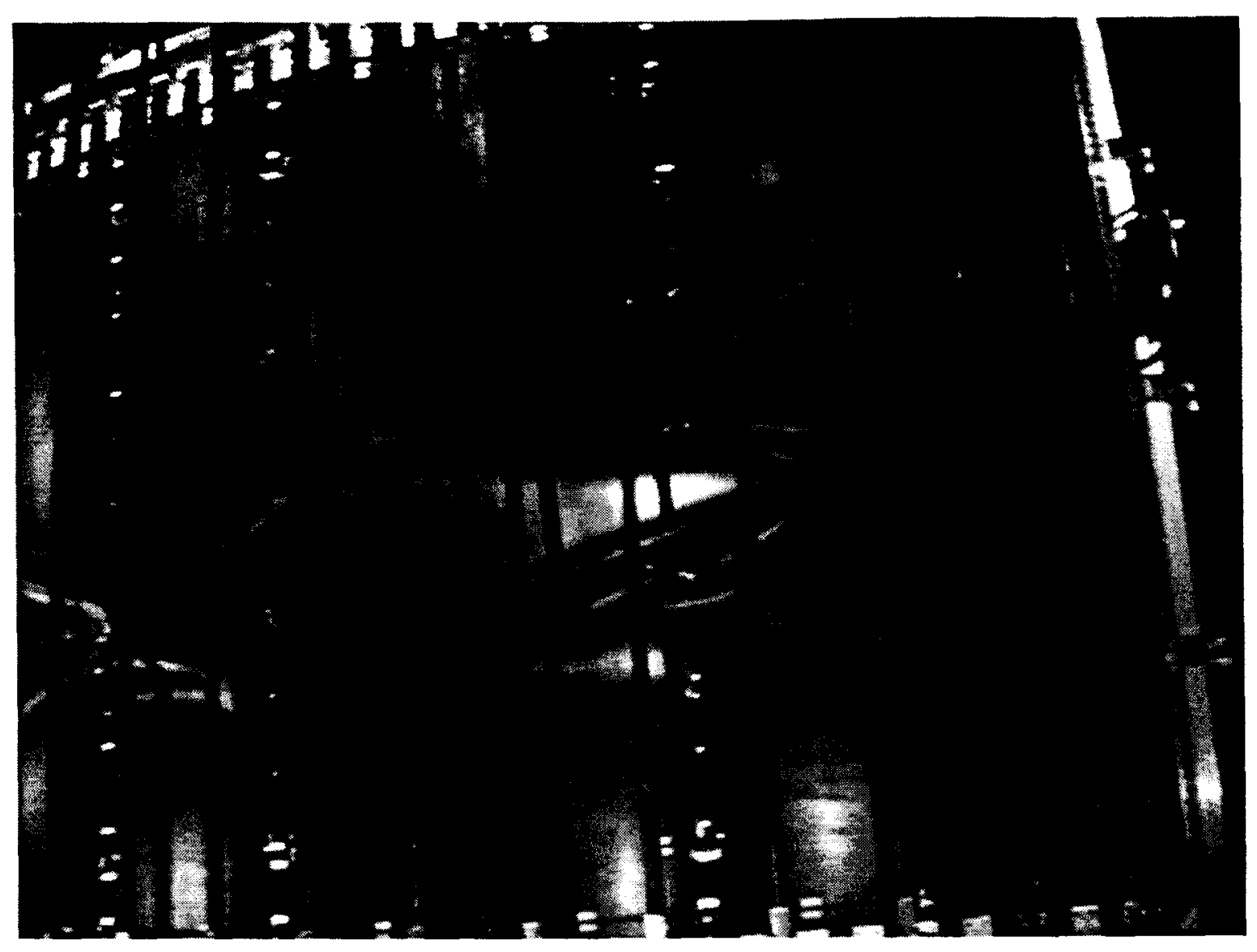

FIGURE 12. Failure of Intertank Test Article.

The linear static finite element analysis results indicated that the first possible failure mode would be buckling of the panel skin between the stiffeners at a load level approximately 1.6 times the design limit load. Since a nonlinear analysis has not been completed, post-buckling behavior of the test article was not determined.

Preliminary examination of the test article and the recorded data indicate that premature failure was initiated by separation of the stiffeners from the panel skin between the third and fourth ring frames (third bay) from the loading end of the test article. Photographs of failed hat-stiffeners are shown in figure 13. A few of the hat-stiffeners were completely severed and separated from the panel skin as shown in the photograph on the left of figure 13. However, most of the hat-stiffeners separated from the panel skin over a small portion of the area between the ring frames. The hat-stiffeners experienced some crippling damage, but were not completely severed as shown in the photograph on the right side of figure 13. The stiffeners near the center of the circular arch were more severely damaged and separated from the skin than were the stiffeners near the sides of the panel. The outer two stiffeners on each side of the test article did not show any visible damage nor evident that the stiffeners had separated from the panel skin. Close examination of the test article after the test revealed that there was damage in the second panel bay between the second and third ring frames in the region where buckling was noted from observation of the video tape. Three or four of the stiffeners were partially separated from the panel skin but the stiffeners did not have any visible crippling damage.

Sub-element tests were conducted at LaRC prior to fabrication of the test article to verify that the proposed fabrication procedure would result in good structural joints between the hat-stiffeners and the skin, and to determine crippling loads for the hat-stiffener construction. Sub-element crippling test results showed higher failure strain values than that obtained during the component test. Preliminary conclusions from the full-scale tests are that the secondary bonding of the hat-stiffener to the panel skin on the test article were not as good as that obtained with the sub-element test specimens. Examination of the failure surface between the hat-stifferers and the skin indicate that insufficient adhesive may have been used in the joint. Sub-element test specimens will be cut from the test article in areas where there is no apparent damage and tested to evaluate the attachment of the stiffeners to the panel skin for 
the test article. Results from these post-tests will be compared with the original sub-element test results to evaluate the quality of construction of the test article.
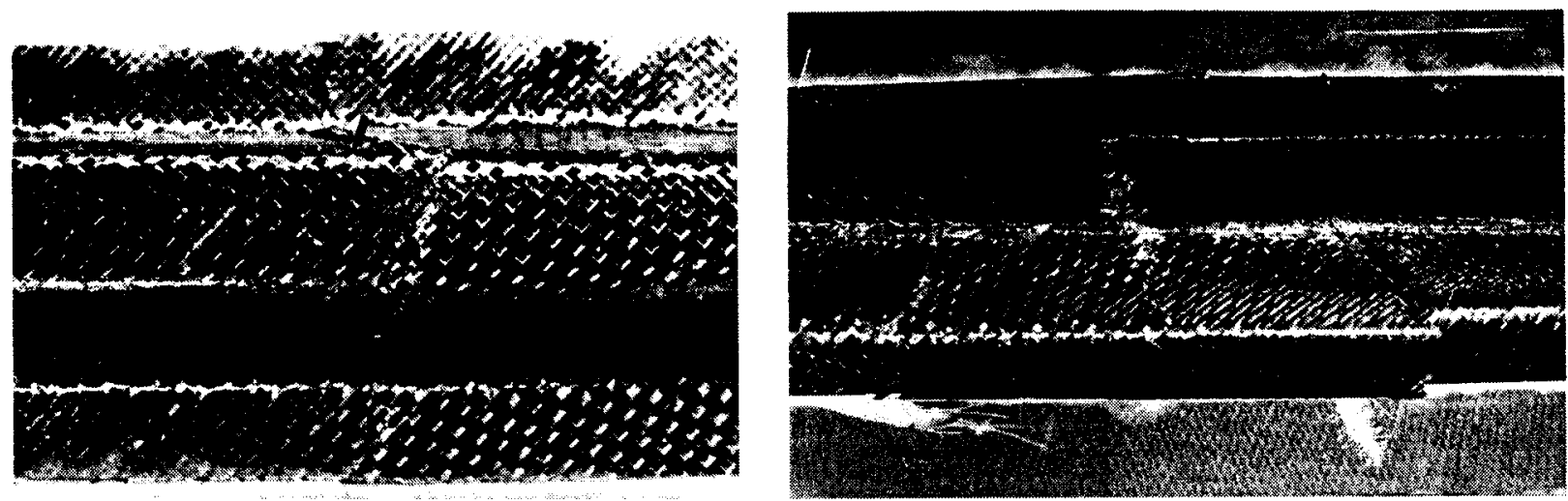

FIGURE 13. Failure of Hat-Stiffeners on Intertank Test Article

Measured and predicted strain gage results at four locations in the center of the third bay (figure 9, section b-b) of the test article, are shown in figures 14-17. The data shown in figure 14 were obtained on the hat-stiffener (number one) next to the left side of the test article. The data shown in figures 15 through 17 were obtained on hat-stiffeners near the quarter section (stiffener number 10), at the 40 percent location (stiffener number 15) and the center (stiffener number 22) of the test article. At each location, measured strain results are shown at four points on the hat-stiffener and skin as indicated by curves $A$ through $D$. The strain variations on the panel skin are given by curve $A$, on the stiffener sidewalls by curves B and D and on the stiffener cap by curve C. Only one predicted strain value is given on each figure since the analysis shows approximately uniform strain through the cross-section of the hat stiffener and panel skin.

Measured strain values shown in figures 14-17 show linear increases in strain with applied loads from approximately 20 percent of the design limit load up to failure. Non-linear variations in the measured strains at loads below 20 percent of the design limit load are due to inadequate control of the hydraulic acturators which resulted in wide variations in the load applied by the individual actuators. At loads above 20 percent of design limit load, good control of the actuators was achieved as indicated in figure 10. The strain values shown in figure 16 for location $D$ are suspect and will be ignored until verified to be accurate.

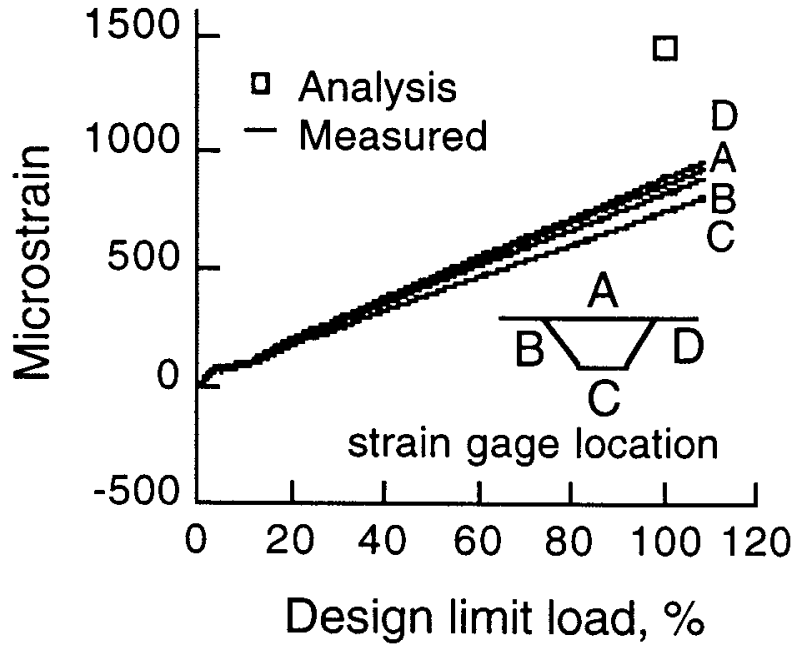

FIGURE 14. Measured and Predicted Strain on HatStiffener Number 1.

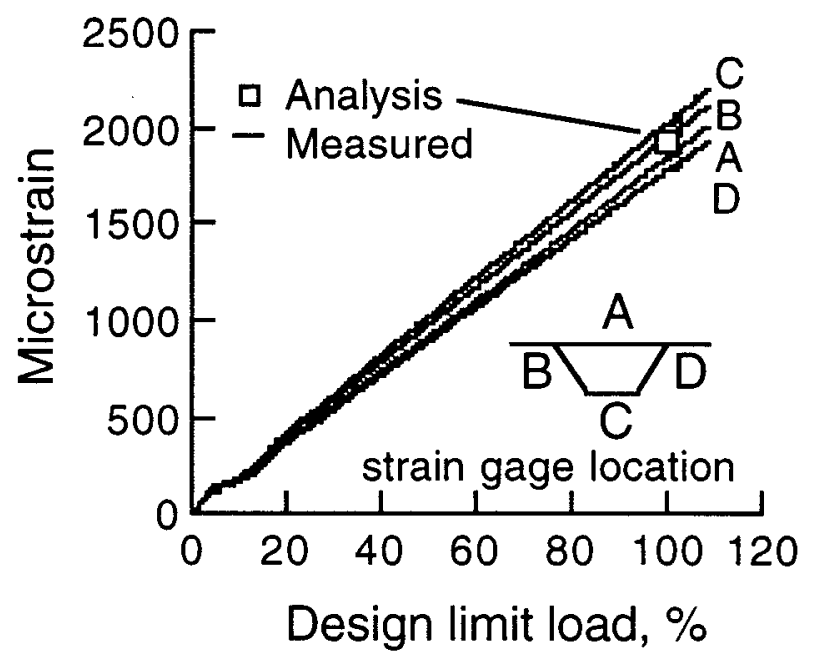

FIGURE 15. Measured and Predicted Strain on HatStiffener Number 10.

The measured strain values shown for the four cross-section locations (figures 14-17) exhibit significant variations ( 15 to 20 percent) in strain between the skin (A), stiffener sidewalls (B and D), and stiffener cap (C). Also the highest and lowest strain values for a given cross-section occur on the stiffener sidewalls or cap depending on the 
cross-section location. For example, the highest strain values in figure 15 are exhibited on the stiffener cap, whereas, in figure 17 the highest strain values are exhibited on the stiffener sidewall. Note that the strain values exhibited for the skin (A) in figures 14-17 are bracketed by the strain values for the other structural elements.

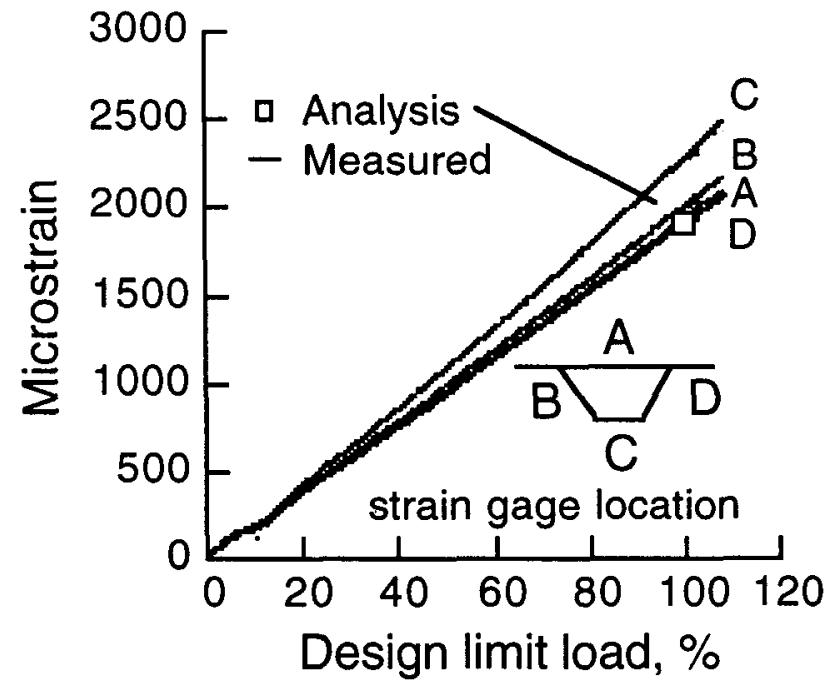

FIGURE 16. Measured and Predicted Strain on HatStiffener Number 15.

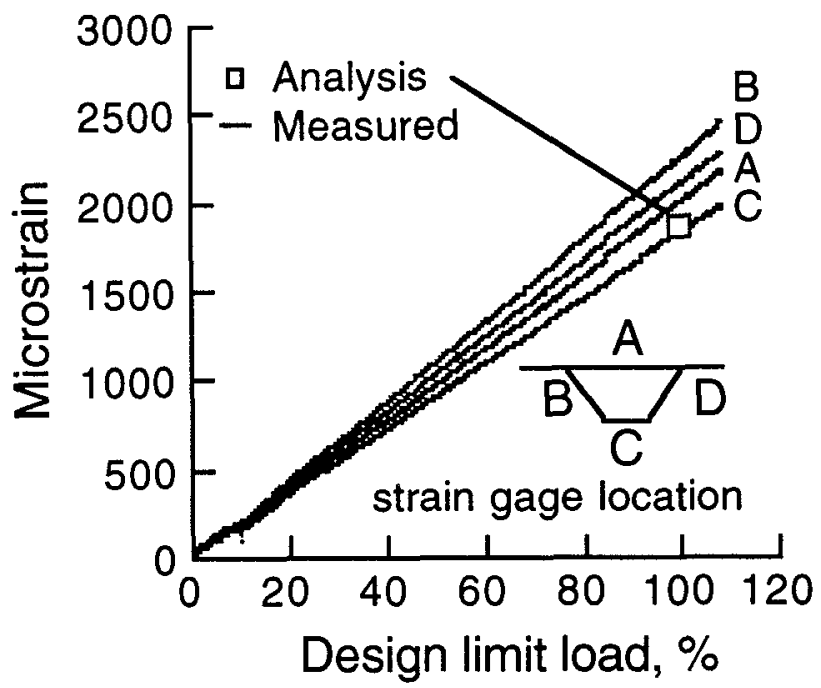

FIGURE 17. Measured and Predicted Strain on HatStiffener in Center of Test Article.

The predicted strain values shown in figures 15-17 for the three cross-section locations away from the side edge of the test article are in good agreement with the measured values. However, the predicted strain value for the crosssection near the test article side edge shown in figure 14 is approximately 50 percent higher than the measure values at design limit load. This discrepency between the predicted and measured strain values near the side edge of the test article is a result of the the finite element model not accounting for the close-out of the side edges of the test article.

\section{SUMMARY}

The use of graphite-composites as primary structure is essential for the development of a cost effective single-stageto-orbit reusable launch vehicle (RLV). A full-scale segment of a graphite-composite intertank was designed and fabricated by a Boeing North American/Northrop-Grumman industry team and tested at NASA Langley Research Center as a part of the RLV technology development program. The intertank test component was approximately 3.0 $\mathrm{m}$ long by $6.7 \mathrm{~m}$ wide and included slightly less than a $90^{\circ}$ section of a cylindrical intertank. The test article was fabricated using graphite-bismaelimide composite material and consisted of a hat-stiffened skin with five ring frames The stiffeners were secondarily bonded to the panel skin and the ring frames mechanically attached. The test article was loaded to failure with a uniform compression load applied by 21 individually controlled hydraulic actuators. Resistance strain gages, LVDTs, and video cameras were used to measure and record the test results.

The test results verified the structural integrity of the intertank test article up to the design limit load with good correlation between the test and analysis results. However, the test article failed in general skin buckling between the ring frames at a load of 1.08 times design limit load which was considerably lower than the expected failure load. Buckling of the skin was predicted by the linear finite element analysis to occur at approximately 1.6 times the design limit load. The video tape shows that skin buckling initiated in the center of the panel bay and propagated to each side of the test article. Preliminary examination of the test article and the recorded data indicate that premature failure was initiated by separation of the hat-stiffeners from the panel skin. Initial conclusions are that the secondary bond strength between the hat-stiffeners and the panel skin on the full-scale test article were not as good as that expected based on sub-element tests conducted prior to fabrication of the full-scale test article. Subelement specimens from an undamaged section of the full-scale test article will be tested to evaluate the attachment of the stiffeners to the panel skin for the full-scale test article. 


\section{Acknowledgments}

Design, fabrication, and analysis of the intertank test article was performed by a Boeing North American/NorthropGrumman industry team led by Mr. John Pulley, Program Manager, Boeing North American and Mr. Daniel Suh, Project Engineer,

Northrop-Grumman. The authors acknowledge the following personnel at NASA Langly Research Center for their contribution in conducting the tests and evaluating the results: Winfred S. Kenner, Marshall Rouse, William S. Small, and Russell W. Smith.

\section{References}

Anon. (1994) “Access To Space Study" Summary Report. Office of Space Systems Development, NASA Headquarters, January, 1994.

Beckey, Ivan (1994) "Access To Space," Presented at The 45th Congress of the International Astronautical Federation, October 9-24, 1994, Jerusalem, Israel.

Freeman, Delma C. Jr., Douglas O. Stanley, Charles J. Camarda, Roger A. Lepsch, and Stephen A. Cook (1994) "Single-Stage-To-Orbit--A Step Closer," Presented at The 45th Congress of the International Astronautical Federation, October 9-24, 1994, Jerusalem, Israel.

Sawyer, James Wayne, (1996) "Graphite-Composite Primary Structure for Reusable Launch Vehicles," Presented at The 1996 AIAA Space Programs and Technologies Conference, September 24-26, 1996, Huntsville, Alabama.

Suh, Daniel E., Vincent A. Biagiotti, Donald J. Prior, and James S. Yahiro (1996) "Critical Technologies in Composite Wing and Intertank Primary Structures Supports RLV Success," Presented at The 37th AIAA Structures and Materials Conference, April 15-17, 1996, Salt Lake City, Utah, Paper No. 96-1425.

Sawyer, James Wayne, Harold Bush, Thomas R. Sutter (1997) "Experimental Investigation of a GraphiteComposite Wing-Box section for a Reusable Launch Vehicle," Presented at The Space Technology and Applications International Forum, CONF-970115, January 26-30, 1997, M.S. El-Genk, ed. American Institute of Physics, New York, AIP Conference Procedings No. 387, Vol. 1 Part Three, pg. 1245-1258.

Biagiotti, V. A., J. S. Yahiro, Daniel E. Suh, Eric R. Hodges, Donald J. Prior (1997) "Design Development of Graphite Primary Structures Enables SSTO Success, "Presented at The Space Technology and Applications International Forum, CONF-970115, January 26-30, 1997, M.S. El-Genk, ed. American Institute of Physics, New York, AIP Conference Procedings No. 387, Vol. 1 Part Three, pg. 1239-1244. 